\title{
The Cointegration Analysis of the Population Migration and the Economic Growth in Xinjiang
}

\author{
Ting Zou ${ }^{1, a}$ and Haiying Ma ${ }^{2, b^{*}}$ \\ ${ }^{1,2}$ School of Economics, Northwest University for Nationalities, Lanzhou (730124), P.R.China \\ a1269801382@qq.com, 'lxmahaiying8888@163.com
}

Keywords: Population migration; Stationarity; Economy growth; Xinjiang

\begin{abstract}
Migration bring large labor to help resolving the problem of the shortage of effective labor supply in Xinjiang, and promotes Xinjiang's economic development. This paper firstly select relative data during 1990-2007 in Xinjiang. Then, we use the unit root test, cointegration test and the granger causality test and other statistical methods to study the Xinjiang population migration and economic growth, as well as the relationship between them. Finally, according to the results, I put forward some corresponding countermeasures.
\end{abstract}

\section{Introduction}

Although Xinjiang has been not as developed as the east area from a long time, it is a province of huge population migration. It is shown as a net in-migration. The net in-migration of the population has played a significant role in the economic development of Xinjiang. This paper selects the existing data since the reforms and the opening up of china, by using the advancing edge economic analysis theory-cointegration analysis, and the model of Frank (2005) to test the relationship between population migration and economic growth, in order to get a new perspective to re-examine the relationship between them. Finally, I aim at providing the basis for scientific decision to adjust the number of population migration for a long-term economic growth in Xinjiang.

Because of the different level of population migration and economic development in various regions of china, the regional characteristics may be different from the overall characteristics of china. However, existing research on the relationship between population migration and economic growth mostly is the overall investigation, in a single area of the study of the relationship between population migration and economic literature is very little, and a comprehensive investigation of the relationship between the two quantities are also not many. Therefore, it is necessary to make a comprehensive study on the system of regional population migration and economic growth.

\section{Empirical Analysis}

Index Selection and Data Collection. With net in-migration population ( $\mathrm{pm}$ ) measure actual population inflows, with per capita GDP to measure the degree of economic development. Data from 50 year of Xinjiang Statistical Yearbook and the calendar year of Xinjiang Statistical Yearbook.

Test of Different Variances. If the random error term of linear regression model exists heteroscedasticity, and it will have a significant influence on the model parameter estimation, model checking and the application of the model. So we need to test the different variance of the data, in order to facilitate the effective establishment of the following model. In this paper, we use Park test of the residual regression test for heteroscedasticity test.

Under the significant level of $0.05, \mathrm{P}=0.1294$, which indicates that there is no heteroscedasticity in the model, that is, there is no need for the data to carry on the logarithm transformation, which can be modeled directly from the original data.

The Unit Root Test. In order to judge the stationarity of time series, we need to carry out unit root test for the related variables. so far, there are many methods of unit root test and have special 
characteristics respectively, in this paper we use the more commonly used ADF-Fisher Chi-square method for testing. The validation result is shown in table.

Table 1 ADF Test Results

\begin{tabular}{lllrrrr}
\hline \multirow{2}{*}{ Variables } & $\begin{array}{l}\text { Inspection } \\
\text { Type }(\mathrm{c}, \mathrm{t}, \mathrm{k})\end{array}$ & $\begin{array}{l}\text { ADF } \\
\text { Statistical } \\
\text { Value }\end{array}$ & \multicolumn{2}{c}{ Criticality Value } & & \\
& $(\mathrm{c}, 0,0)$ & -1.5431 & -3.6793 & -2.9678 & -2.6223 & no \\
\hline $\begin{array}{l}\text { PM Original } \\
\text { sequence }\end{array}$ & $(\mathrm{c}, 0,0)$ & -7.7843 & -3.6892 & -3.0299 & -2.9719 & yes \\
$\begin{array}{l}\text { PM first sequence } \\
\text { PM Second sequence }\end{array}$ & $(\mathrm{c}, 0,0)$ & -10.723 & -3.6999 & -2.9763 & -2.6274 & yes \\
$\begin{array}{l}\text { CGDP Original } \\
\text { sequence }\end{array}$ & $(\mathrm{c}, 0,0)$ & 11.4253 & -3.6793 & -2.9678 & -2.6229 & no \\
$\begin{array}{l}\text { CGDP first sequence } \\
\text { CGDP Second }\end{array}$ & $(\mathrm{c}, \mathrm{t}, 11)$ & -3.9708 & -4.6679 & -3.7332 & -3.3103 & yes \\
sequence & $(\mathrm{c}, 0,0)$ & -6.3699 & -3.6998 & -2.9763 & -2.6274 & yes \\
\hline
\end{tabular}

From the test results can be seen, the original sequences of PMt and CGDPt are non-stationary sequences, but after the first difference and the second difference all pass the 5\%-10\% threshold of the ADF test, they are stationary sequences. Therefore, $\triangle \mathrm{PMt}$ and $\triangle \mathrm{CGDPt}$ are stationary sequences, and get the same order, namely $\mathrm{PM} \sim \mathrm{I}(1), \mathrm{CGDP} \sim \mathrm{I}(1)$. This provides a necessary condition for cointegration test of time series.

Cointegration Test. Through the above analysis, we can see that the variables meet the premise of cointegration test, according to the Engle-Granger two step method, the PM, CGDP variables cointegration test. If they are cointegrated, there is a long-term stable equilibrium relationship between them.

The first step: Use the OLS methold to cointegration regression to obtain the cointegration equation (long-run equilibrium equation).

$$
\begin{gathered}
\mathrm{CGDP}=1333.567804+576.4149524 * \mathrm{PM} \quad(1) \\
(1.929074) \quad(7.283514) \\
(0.000) \\
\text { Ad- } \mathrm{R}^{2}=0.654532 \mathrm{~F}=53.04958 \mathrm{DW}=1.050887 \\
\mathrm{PM}=0.4895301547+0.001135522991 * \mathrm{CGDP} \\
(0.475922) \quad(7.283514) \\
(0.000) \\
\text { Ad- } \mathrm{R}^{2}=0.654532 \mathrm{~F}=53.04958 \mathrm{DW}=1.604894
\end{gathered}
$$

From the regression results, the $\mathrm{t}$ test and $\mathrm{F}$ test of the above regression equation are significant at the $1 \%$ level, $\mathrm{F}$ value is very large, and the regression results are ideal.

The second steps: The stability of the residual sequence of the regression equation is examined. The residual sequence of the cointegration regression equation is E1, e2. If the residual sequence is stationary, the relationship between variables is cointegration between variables. It is cointegration on the residual sequence using ADF stationary test, the results are shown in table 2. 
Table2: ADF test results of the residual sequence

\begin{tabular}{lllcccc}
\hline \multirow{2}{*}{ Variables } & Inspection & ADF Statistical & \multicolumn{2}{l}{ Criticality Value } & \multicolumn{2}{c}{ Stationarity } \\
& Type $(\mathrm{c}, \mathrm{t}, \mathrm{k})$ & Value & $1 \%$ & $5 \%$ & $10 \%$ & \\
\hline E1 & $(\mathrm{c}, 0,0)$ & -3.4407 & -2.64712 & -1.95291 & -1.610011 & yes \\
E2 & $(\mathrm{c}, 0,0)$ & -4.618129 & -2.64712 & -1.95291 & -1.610011 & yes \\
\hline
\end{tabular}

As can be seen from Table 2, The covariance regression equation (1) (2) is based on the ADF test at the $1 \% \sim 10 \%$ significance level, it can be considered that the E1 and E2 of the residual sequence are stationary, that is, there is a cointegration relationship between the sequences of $\mathrm{E} 1 \sim \mathrm{I}(0), \mathrm{E} 2 \sim \mathrm{I}(0)$, i.e., there is a long-term equilibrium relationship between population migration and per capita GDP . This also proves that the variable selection is reasonable, with the economic significance of the regression coefficients. From the cointegration equation (1) we can see that coefficient of net migration of the population is 576.42 , that is, the long-term elasticity of population migration of per capita GDP is about 576.42, indicating that in the long run, the per capita GDP will increase by 576.42 percentage points when the net immigration of population increased by 1 percentage points . There is a high degree of correlation between the them, that is , the net migration of population has played a considerable role in the growth of per capita GDP; From the cointegration equation 2 it can be seen that the coefficient of per capita GDP is 0.0011 , that is , The long-term elasticity of per capita GDP of population migration is about 0.0011 , indicating that in the long run, the net migration of population will increase by 0.0011 percentage points when per capita GDP increase by 1 percentage points. The relationship between them shows that the growth of Xinjiang' s economy to a certain extent led to the net migration of the population. This conclusion is also same with LU, PU Minggen (2008) research results.

Granger Causality Tests. According to the analysis method of Grainger causality, establish two variables PM, CGDP model, testing the original hypothesis, because the Grange causality test is very sensitive to the order of lagging behind the original hypothesis, according to the previous AIC criterion and determine the lag order number. Results of Granger causality test between PM, CGDP are shown in Table 3.

Table 3 Results of Granger causality test between sequences

\begin{tabular}{llllll}
\hline Null hypothesis & $\begin{array}{l}\text { lag } \\
\text { phase }\end{array}$ & F value & P value & policy & Causal conclusion \\
\hline CGDP is not the cause of PM & 0 & 7.93511 & 0.00239 & refuse & CGDP is the cause of PM \\
PM is not the cause of CGDP & & 0.0934 & 0.91118 & accept & CGDP is the cause of PM \\
CGDP is not the cause of PM & 1 & 16.9796 & 0.00034 & refuse & CGDP is the cause of PM \\
PM is not the cause of CGDP & & 0.000083 & 0.9928 & accept & CGDP is the cause of PM \\
CGDP is not the cause of PM & 2 & 7.93511 & 0.00239 & refuse & CGDP is the cause of PM \\
PM is not the cause of CGDP & & 0.0934 & 0.91118 & accept & CGDP is the cause of PM \\
CGDP is not the cause of PM & 3 & 12.7163 & 0.000071 & accept & CGDP is the cause of PM \\
PM is not the cause of CGDP & & 0.3864 & 0.76398 & refuse & CGDP is the cause of PM \\
\hline
\end{tabular}

From table 3 we can observe : In the lag 0-3 period, the test results are all acceptable CGDP $\rightarrow \mathrm{PM}$, but refusing $\mathrm{PM} \rightarrow \mathrm{CGDP}$, which means per capita GDP is the Granger cause of population mobility, that is , there is a one-way causal relationship between PM and CGDP. This shows that there is a basic scale of population migration in Xinjiang, that is, the net migration of population is not affected by economic growth. This point only from the growth potential of the Xinjiang oasis's economic to explain, that is to say, the Xinjiang's economic growth has not yet reached a reasonable level of potential economic growth, population expectations are higher. 


\section{Conclusions}

Through the stationary test, it is found that the net population mobility and per capita GDP of Xinjiang are non-stationary time series, however, the first order difference sequence has reached the stability requirements, they are cointegrated and there is a long-term equilibrium relationship between them; through Granger empirical causal relationship analysis, confirmed the existence of a one-way causal relationship between the population and the per capita net migration rate of GDP, instead of two-way causality. The primary reason for this result is that we only use 1978-2007 30 sets of data for analysis and testing, the number of time series data requirements for the number of small, only belongs to small sample. In addition, the population migration data only consider the long-term population, and the floating population is not considered, the existence of these objective facts, to a certain extent, affected the results of empirical analysis. It should be noted that there is no Granger causality between variables does not mean that there is no relationship between the two, we already know that there is a long-term equilibrium relationship between them.

In order to enhance the ability of Xinjiang's economic growth, promote the coordinated development of regional economy and population migration, efforts should be made in the following aspects: (1) To promote the city's economic development and industrial structure optimization, creating employment opportunities for city. (2) To increase the incomes of the people as soon as possible and improve the level of people's lives, especially to improve the treatment of high quality talents. (3) Strive to create conditions for the transfer of rural surplus labor to cities and towns. (4) To strengthen the city's economic radiation capacity, improve the urban facilities environment, and create a good image of the city.

\section{References}

[1] Fan L., Measuring Interprovincial Flows of Human Capital in China: 1995-2000, Population Research and Policy Review. 3(2009)67-387.

[2] Li S., Population migration and urbanization in China: A comparative analysis of the 1990 population census and the 1995 national one percent sample population survey, International Migration Review.7 (2004) 655-685.

[3] Meng Xin, the Informal Sector and Rural-Urban Migration: A Chinese Case Study, Asian Economic Journal. 15(2001) 71-89.

[4] Wang F., Zuo X., Inside China's Cities: Institutional Barriers and Opportunities for Urban Migrants, The American Economic Review. 2(1999)276-280.

[5] Wu Z., Yao S., Intermigration and intermigration in China: A theoretical and empirical analysis, China Economic Review. 4 (2003)371-385.

[6] Zhang K. H., Song S., Rural-urban migration and urbanization in China: Evidence from time-series and cross-section analyses, China Economic Review. 4(2004) 386-400.

[7] Zhao Z., Migration, labor market flexibility, and wage determination in China: A review, Developing Economies. 2(2005) 285-312.

[8] Wang Guixin, Analysis of the relationship between population migration and regional economic development in China, Population and economy. 8(1996)78-90.

[9] Yang Zheng, Tong Yufen, Study on the inter provincial Migration of population in Xinjiang, Urumqi, Xinjiang people press, 1996.

[10] Wang Ying, Population mobility and social economic development in Xinjiang, Journal of Xinjiang University, Social Science Edition, 2001.

[11]Zhang Yan, Guo Xiaoyuan, Analysis of the interaction between population and economic development in Xinjiang, Xinjiang Statistics, 2000. 